\title{
Suppression of Par-4 Protects Human Renal Proximal Tubule Cells from Apoptosis Induced by Oxidative Stress
}

\author{
Bin Sun ${ }^{\mathrm{a}}$ Chao Lu ${ }^{\mathrm{b}}$ Guo-Ping Zhou ${ }^{\mathrm{b}}$ Chang-Ying Xing ${ }^{\mathrm{a}}$ \\ a Division of Nephrology, Department of Internal Medicine, and ${ }^{b}$ Division of Paediatrics, The First Affiliated Hospital \\ of Nanjing Medical University, Nanjing, China
}

\section{Key Words}

Apoptosis $\cdot$ Human renal proximal tubule cells $\cdot$ Oxidative stress $\cdot$ PI3K/Akt signal transduction $\cdot$ Prostate apoptosis response factor- $4 \cdot$ siRNA experiments

\begin{abstract}
Background: Oxidative stress is an important inducer of cell apoptosis and plays a key role in the development of renal inflammation. The prostate apoptosis response factor- 4 (Par-4) gene was originally identified in prostate cells undergoing apoptosis. Subsequently, Par-4 was found to possess potent pro-apoptotic activity in various cellular systems. However, it remains unclear whether Par- 4 is involved in oxidant injury of renal tubular epithelial cells. Aims: To determine the role of Par- 4 in renal proximal tubular cell apoptosis induced by oxidative stress. Methods: Par-4 gene expression was silenced by small interfering RNA. Renal proximal tubular cells were then exposed to hydrogen peroxide and the effect of Par-4 silencing on apoptosis and expression of phosphorylated Akt and vascular endothelial growth factor was determined. Results: Hydrogen peroxide induced apoptosis and increased Par-4 expression in human renal proximal tubular epithelial cells. Par-4 silencing significantly protected renal proximal tubular cells from apoptosis via activating the PI3K/Akt signaling pathway as Akt phosphorylation was enhanced. Par-4 silencing also ameliorated
\end{abstract}

the downregulation of vascular endothelial growth factor expression induced by oxidative stress. Conclusion: Par-4 gene silencing resulted in PI3K/Akt signaling-dependent inhibition of renal proximal tubular cell apoptosis following oxidative stress.

Copyright ๑ 2010 S. Karger AG, Basel

\section{Introduction}

Oxidative stress plays an important role in the pathophysiology of various forms of renal disease. The resulting reactive oxygen species (ROS) have been shown to mediate renal injury in toxic, metabolic, ischemic and inflammatory renal diseases [1-3]. The proximal tubules are a primary target of injury in various renal diseases potentially mediated by oxidant injury [4-9]. For example, ischemia-reperfusion injury, a common cause of acute renal failure, is characterized by the excessive production of ROS and consequent tubular cell apoptosis and necrosis [10-12]. Despite much experimental and clinical study, the mechanisms involved in oxidative stress-induced apoptosis are largely unexplored. The identification of novel regulatory mediators of oxidative stress-induced apoptosis may lead to new therapies for protecting renal proximal tubular cells against oxidative stress.

\section{KARGER}

Fax +4161306 1234 E-Mail karger@karger.ch www.karger.com
Chang-Ying Xing

Division of Nephrology, Department of Internal Medicine

The First Affiliated Hospital of Nanjing Medical University

Guangzhou Road 300, Nanjing 210029, Jiangsu (China)

Tel. +86 1395165 3266, Fax +86 258629 1273, E-Mail cyxing_nanjing@163.com 
Prostate apoptosis response factor-4 (Par-4) was initially identified in human prostate cell lines. Subsequently, Par- 4 was found to possess potent pro-apoptotic activity in various cellular systems in response to numerous stimuli. The Par-4 gene maps to chromosome 12q21, a region frequently deleted in malignant tumors, and encodes a $38-\mathrm{kD}$ a protein. Par- 4 contains a leucine zipper domain in the carboxyterminal region that interacts with a variety of proteins, including the atypical protein kinases (aPKCs), $\mathrm{PKC} \zeta$ and $\mathrm{PKCl} / \mathrm{I}$. Par- 4 protein localizes predominantly to the nucleus but is also present in the cytoplasm. However, nuclear entry of Par- 4 was essential for its pro-apoptotic activity [13-17]. Recently, Lee et al. [18] demonstrated that the ectopic expression of Par-4 sensitized human renal cancer cells to apoptosis induced by tumor necrosis factor-related apoptosis-inducing ligand (TRAIL). However, it remains unclear whether Par4 is involved in the apoptosis of renal tubular epithelial cells induced by oxidant injury.

The serine/threonine kinase Akt is a critical component of the intracellular signaling pathway that supports cell survival and inhibits apoptosis [19-21]. The nonphosphorylated form of AKT is virtually inactive, and phosphorylation at Ser-473 generates active pAKT [1922]. Vascular endothelial growth factor (VEGF) is a critical mediator of angiogenesis $[20,21]$ and plays a role in the pathogenesis of diabetic retinopathy, nephropathy and vascular disease [23, 24]. VEGF is both an autocrine and paracrine factor and VEGF expression is increased in the kidneys of patients with type 1 [25] and type 2 diabetes [26]. In this context, increased VEGF expression is involved in glomerular and tubular hypertrophy, proteinuria and glomerular hyperfiltration [23, 24]. Activation of the PI3K/Akt pathway increases transcriptional activation of the VEGF promoter via the transcription factor Sp1 [27]. However, little is known about the effect of oxidative stress on the regulation of VEGF expression in human renal tubular epithelial cells.

In the present study, we provide evidence that the silencing of Par- 4 gene expression promotes PI3K/Akt signal transduction and protects renal proximal tubular cells from apoptosis induced by oxidative stress.

\section{Materials and Methods}

\section{Chemicals and Reagents}

Fetal bovine serum and Dulbecco's modified Eagle's medium were obtained from GibcoBRL (Gaithersburg, Md., USA). Ribonuclease (RNase) and propidium iodide (PI) were purchased from Sigma Chemical (St. Louis, Mo., USA). Caspase-3 assay kits and the caspase-3 inhibitor were purchased from Calbiochem (Cambridge, Mass., USA). Antibodies against Par-4, Akt, phosphorylated Akt (Ser-473) and VEGF were purchased from Santa Cruz Biotechnology (Santa Cruz, Calif., USA). Lipofectamine was purchased from Invitrogen Life Technologies Inc. (Carlsbad, Calif., USA).

\section{Cell Culture}

Commercially available human proximal tubular epithelial cells prepared from human kidney biopsies were purchased from Cambrex Biosciences (East Rutherford, N.J., USA). Renal proximal tubular epithelial cells were grown in a renal epithelial growth medium as recommended by the manufacturer. HK-2 cells, a human renal proximal tubular epithelial cell line, were cultured in Dulbecco's modified Eagle's medium containing 10\% fetal bovine serum, $100 \mathrm{U} / \mathrm{ml}$ penicillin, and $100 \mu \mathrm{g} / \mathrm{ml}$ streptomycin. Subconfluent cells were washed once and made quiescent by incubation in serum- and supplement-free medium for 24 or $48 \mathrm{~h}$ prior to experiments.

Preparation of Nuclear Extracts and Whole Cell Extracts

Cells were washed twice with ice-cold phosphate-buffered saline and collected after centrifugation at $300 \mathrm{~g}$ for $5 \mathrm{~min}$. Cells were resuspended in ice-cold buffer containing $10 \mathrm{mM}$ Hepes, $\mathrm{pH}$ 7.8, $10 \mathrm{mM} \mathrm{KCl}, 1.5 \mathrm{mM} \mathrm{MgCl}_{2}, 1 \mathrm{mM}$ dithiothreitol, $0.1 \mathrm{mM}$ EDTA, $1 \mathrm{mM}$ phenylmethylsulfonyl fluoride, $10 \mu \mathrm{g} / \mathrm{ml}$ aprotinin, and $2 \mu \mathrm{g} / \mathrm{ml}$ pepstatin and kept on ice for $15 \mathrm{~min}$. Cells were lysed in $0.1 \%$ Nonidet P-40 and vortexed for $10 \mathrm{~s}$, and the nuclear pellet was recovered after centrifugation at $13,000 \mathrm{~g}$ for $10 \mathrm{~s}$ at $4^{\circ} \mathrm{C}$. The nuclear pellet was resuspended in ice-cold buffer containing 20 mM Hepes, pH 7.8, 0.4 M NaCl, 1 mM EDTA, $1.5 \mathrm{mM} \mathrm{MgCl}_{2}, 1 \mathrm{mM}$ dithiothreitol, $20 \%$ glycerol, $1 \mathrm{mM}$ phenylmethylsulfonyl fluoride, $10 \mu \mathrm{g} / \mathrm{ml}$ aprotinin, and $2 \mu \mathrm{g} / \mathrm{ml}$ pepstatin and incubated on ice for $20 \mathrm{~min}$ with shaking. Nuclear extracts were retained after centrifugation at $14,000 \mathrm{rpm}$ for $5 \mathrm{~min}$ at $4{ }^{\circ} \mathrm{C}$, and the supernatant was separated into aliquots and stored at $-80^{\circ} \mathrm{C}$. Protein concentration was determined by the Bradford method (Bio-Rad).

Whole cell extracts were prepared by sonication in Laemmli sample buffer (10\% glycerol, $5 \% \beta$-mercaptoethanol, $2.3 \%$ SDS, $62.5 \mathrm{~mm}$ Tris- $\mathrm{HCl}$ ( $\mathrm{pH} 6.8$ ), and $0.1 \%$ bromophenol blue).

\section{Western Blot Analysis}

Fifty micrograms of protein from either nuclear or whole cell extracts were loaded on precast SDS/Tris/glycine gels (Bio-Rad). After electrophoresis, proteins were transferred to nitrocellulose membranes for subsequent blotting with the appropriate primary antibody. Membranes were then incubated with the appropriate secondary antibody linked to horseradish peroxidase for $1 \mathrm{~h}$ at room temperature. After washes in TBST ( $25 \mathrm{mM}$ Tris, $\mathrm{pH} 8.0,125$ $\mathrm{mM} \mathrm{NaCl}$ and $0.1 \%$ Tween-20), the blot was incubated in detection reagent (ECL Advance Western blotting detection kit) and exposed to a Hyperfilm ECL film (Pierce). Tubulin and nuclear protein Histone $\mathrm{H} 1$ served as loading controls.

Small Interfering RNA-Based (siRNA) Experiments

A siRNA strategy was employed to silence Par-4 expression in renal proximal tubular cells. The experiments were performed as described previously [17]. Par-4 and scrambled control siRNAs were generated using the procedure of siSTRIKE ${ }^{\mathrm{TM}}$ U6 Hairpin Cloning Systems (Promega). The Par-4 siRNA had the following 
sense strand sequences: 5'-ACCGTCACAGCCGTTTGAATATATT TCAAGAGAATATATTCAAA CGGCTGTGACTTTTTC$3^{\prime}$.

Sense and antisense strands were annealed and ligated into the linearized psiSTRIKE Vector following the manufacturer's directions. Sequence analysis of randomly picked transformed clones was used to confirm the sequence integrity of the Par- 4 shRNA plasmids. Cells were transfected with siRNA or the indicated constructs using Lipofectamine 2000 (Invitrogen) in Opti-MEM I for $24 \mathrm{~h}$, and then the medium was changed back to growth medium for additional incubation. Green fluorescent protein phMGFP vector was co-transfected to determine transfection efficiency by flow cytometry. Forty-eight hours after the transfection, total RNA was prepared using TRI Reagent according to the manufacturer's instructions and used to perform real-time quantitative PCR analysis. The level of target RNA suppression in transfected cells was determined by normalizing for transfection efficiency.

\section{Flow Cytometric Analysis of Apoptosis}

Renal proximal tubular cells were grown to the exponential phase, seeded at a density of $2 \times 10^{6}$ cells per $60-\mathrm{mm}$ dish, and transfected with the indicated concentrations of Par- 4 siRNA plasmids. Cells were then exposed to hydrogen peroxide $\left(\mathrm{H}_{2} \mathrm{O}_{2}\right)$ or control medium for various periods of time. The cells were collected by trypsinization and washed in PBS. After incubation with $5 \mu \mathrm{l}$ of Annexin-V FITC and $10 \mu \mathrm{l}$ of PI $(50 \mu \mathrm{g} / \mathrm{ml})$ at room temperature for $15 \mathrm{~min}$ in the dark, cells were analyzed by flow cytometry using a FACS Calibar. The percentage of cells undergoing apoptosis was calculated and the result presented relative to the levels of apoptosis in controls.

\section{Measurement of Caspase-3 Activity}

Caspase- 3 activity was measured by a caspase- 3 fluorometric protease assay kit (MBL) following the manufacturer's instructions. The fluorogenic synthetic peptide DEVD-7-amino-4-trifluoromethylcoumarin (AFC) was used as a substrate for caspase- 3 and the fluorescence of the released AFC was measured with an excitation wavelength of $360 \mathrm{~nm}$ and an emission wavelength of $530 \mathrm{~nm}$.

\section{Measurement of VEGF Production in the Culture}

Supernatants

The VEGF levels of cell culture supernatant were determined using ELISA kits (R\&D Systems, Minneapolis, Minn., USA) according to the manufacturer's instructions. Briefly, $200 \mu \mathrm{l}$ of cell culture supernatants, controls or standards were added to wells previously coated with human monoclonal anti-VEGF antibody. After $2 \mathrm{~h}$ of incubation, wells were washed and incubated with an enzyme-linked polyclonal anti-VEGF antibody. Following another wash, a substrate solution was added to wells with color development being proportional to the amount of bound VEGF. The plate was read on a Dynex plate reader with an absorbance of 450 $\mathrm{nm}$. Results were calculated from the standard curve generated from several known VEGF concentrations.

\section{Statistical Analysis}

When appropriate, data were expressed as mean \pm SE. Data were analyzed by factorial ANOVA and Fisher's least significant difference test when appropriate. Statistical significance was accepted at $\mathrm{p}<0.05$.

Suppression of Par-4 Protects Human RPTCs from Apoptosis

\section{Results}

\section{$\mathrm{H}_{2} \mathrm{O}_{2}$ Induced Apoptosis and Increased Par-4 \\ Protein Expression in Human Renal Proximal \\ Tubular Epithelial Cells}

We employed $\mathrm{H}_{2} \mathrm{O}_{2}$ to initiate intracellular oxidative stress, as $\mathrm{H}_{2} \mathrm{O}_{2}$ is involved in renal disease and is readily permeable to the plasma membrane [28]. A treatment dose of $0.75 \mathrm{mM} \mathrm{H}_{2} \mathrm{O}_{2}$ was chosen according to preliminary studies (data not shown) and cell apoptosis was monitored over a period of up to $24 \mathrm{~h}$ after $\mathrm{H}_{2} \mathrm{O}_{2}$ treatment. Obvious morphological changes were observed in renal proximal tubular cells within $2 \mathrm{~h}$ with cell shrinkage (the morphological hallmark of apoptosis) developing afterwards. Flow cytometric analysis using FITC-labeled annexin $\mathrm{V}$ to bind phosphatidylserine was employed to assess the level of apoptosis whilst cell viability was assessed by staining with fluorescent PI that binds DNA. Treatment with $0.75 \mathrm{mM} \mathrm{H}_{2} \mathrm{O}_{2}$ induced significant time-dependent apoptosis of renal proximal tubular cells starting $6 \mathrm{~h}$ after $\mathrm{H}_{2} \mathrm{O}_{2}$ treatment (fig. 1).

Western blotting was performed to determine the involvement of Par- 4 in the regulation of $\mathrm{H}_{2} \mathrm{O}_{2}$-induced apoptosis in renal proximal tubule cells. As the pro-apoptotic function of Par- 4 has been attributed to its nuclear translocation, Western blotting was performed on nuclear extracts. $\mathrm{H}_{2} \mathrm{O}_{2}$ induced a time-dependent increase in Par-4 expression in renal proximal tubular cells compared to control with similar results obtained in HK-2 cells (fig. 2a).

Since the activation of caspase- 3 has been implicated as a common downstream effector of diverse apoptotic pathways [29], we examined caspase-3 activation in renal proximal tubule cells exposed to $\mathrm{H}_{2} \mathrm{O}_{2}$. Treatment with $\mathrm{H}_{2} \mathrm{O}_{2}$ significantly increased caspase- 3 activation in both human primary renal proximal tubular epithelial cells and HK-2 cells (fig. 2b).

These data indicate that $\mathrm{H}_{2} \mathrm{O}_{2}$ induced apoptosis in human renal proximal tubular epithelial cells and that this was associated with increased Par-4 protein expression.

\section{Par-4 Suppression Protects Renal Proximal Tubular \\ Cells from $\mathrm{H}_{2} \mathrm{O}_{2}$-Induced Apoptosis via Activation of \\ the PI3K/Akt Signaling Pathway}

To investigate whether Par- 4 suppression may protect renal proximal tubular cells from oxidative stress-induced apoptosis, we performed siRNA experiments. Renal proximal tubular cells were transfected with either Par-4-specific siRNA, control scrambled siRNA, or no 
Fig. 1. $\mathrm{H}_{2} \mathrm{O}_{2}$ induces time-dependent apoptosis in human proximal tubule epithelial cells. Primary human proximal tubular epithelial cells were treated with $\mathrm{H}_{2} \mathrm{O}_{2}(0.75 \mathrm{mM})$ for 0 (control), 6, 12 or $24 \mathrm{~h}$. Flow cytometric analysis was employed to assess the level of apoptosis. ${ }^{*} \mathrm{p}<0.05$ compared to control cells.
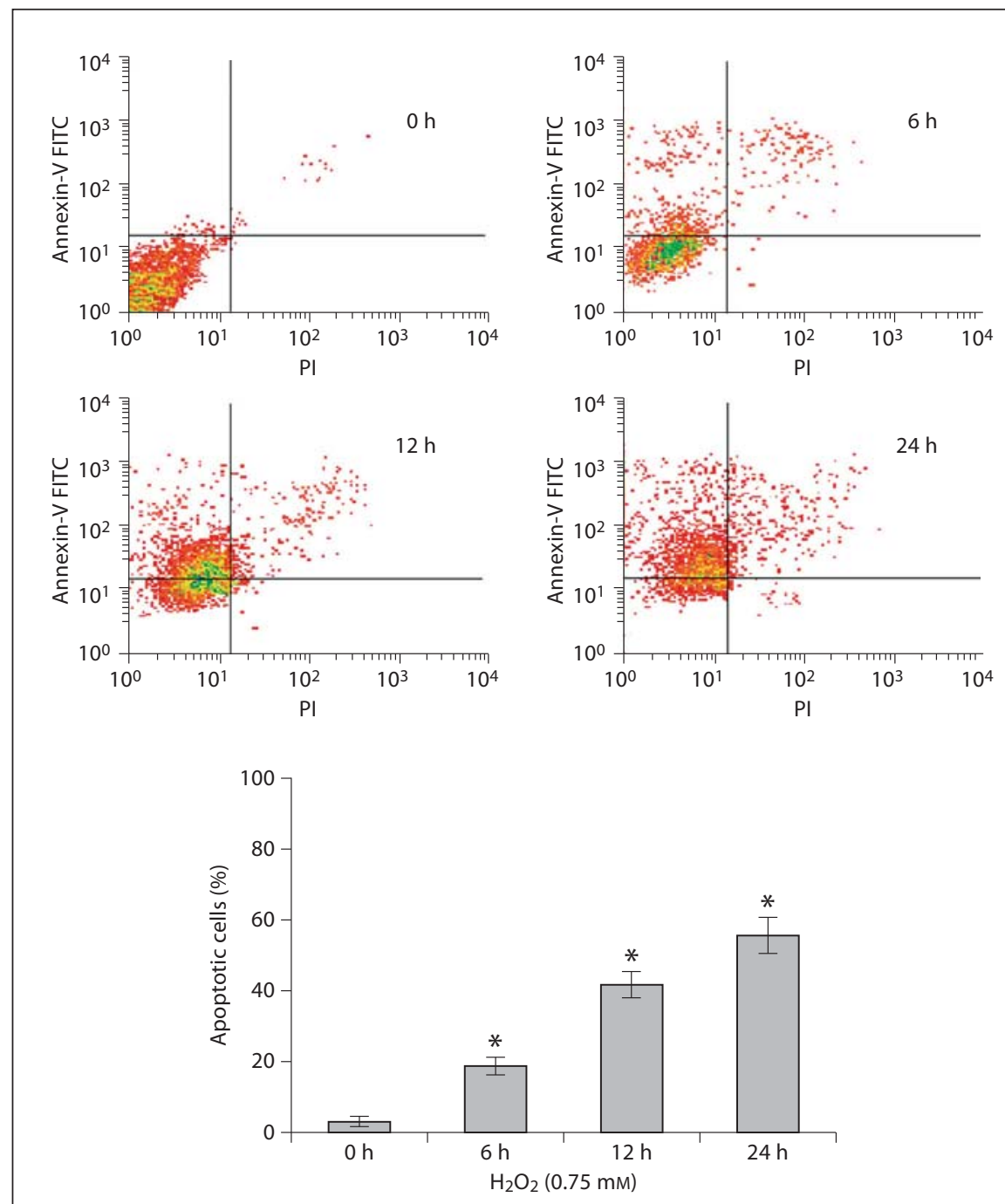

siRNA (mock transfection). Par-4 mRNA and protein expression was assessed by real-time quantitative PCR analysis and Western blotting respectively. Par-4-specific siRNA effectively reduced Par-4 mRNA and protein expression (fig. 3a). Control and Par-4-specific siRNA transfected renal proximal tubular cells were then exposed to $0.75 \mathrm{mM} \mathrm{H}_{2} \mathrm{O}_{2}$ for $24 \mathrm{~h}$. Flow cytometric analysis indicated that the suppression of Par-4 expression significantly attenuated $\mathrm{H}_{2} \mathrm{O}_{2}$-induced apoptosis (fig. $3 \mathrm{~b}$ ).

Because it has been demonstrated that Par- 4 deficiency leads to activation of the Akt pathway in vivo and in several cellular systems $[18,26,27]$, we assessed the effects of Par-4 silencing on the PI3K/Akt signaling pathway in renal proximal tubular cells exposed to $\mathrm{H}_{2} \mathrm{O}_{2}$. Primary renal proximal tubular cells and HK-2 cells were treated with $0.75 \mathrm{mM} \mathrm{H}_{2} \mathrm{O}_{2}$ for between $5 \mathrm{~min}$ and $24 \mathrm{~h}$ at which point lysates were analyzed by Western blotting. $\mathrm{H}_{2} \mathrm{O}_{2}$ treatment increased Akt phosphorylation (Ser-473) that peaked at $10 \mathrm{~min}$ and declined to basal levels within $3 \mathrm{~h}$ (fig. 4a). We then sought to determine whether the antiapoptotic effect of Par-4 suppression was related to sustained activation of the PI3K/AKT signaling pathway. Renal proximal tubular cells were transfected with Par4-specific siRNA followed by treatment with the PI3K inhibitor LY294002 $(20 \mu \mathrm{M})$ or medium alone for $1 \mathrm{~h}$. Then, cells were exposed to $0.75 \mathrm{mM} \mathrm{H}_{2} \mathrm{O}_{2}$ for $10 \mathrm{~min}$ and Akt phosphorylation (Ser-473) detected with Western blotting. Transfection of cells with Par-4-specific siRNA resulted in increased Akt phosphorylation in $\mathrm{H}_{2} \mathrm{O}_{2}$-treated renal proximal tubular cells (fig. 4b). However, LY294002 


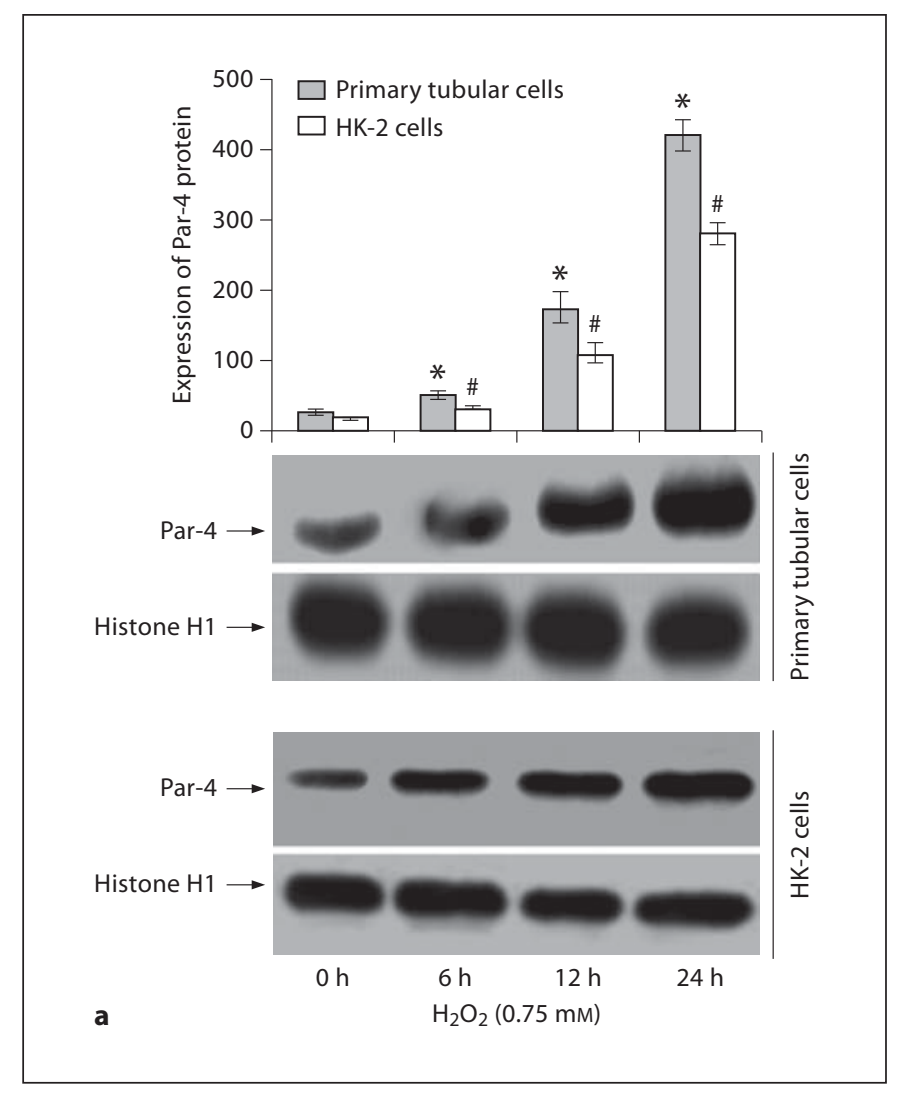

Fig. 2. $\mathrm{H}_{2} \mathrm{O}_{2}$ increases Par- 4 protein expression and caspase- 3 activity in human proximal tubular epithelial cells. a Primary proximal tubular epithelial cells and HK-2 cells were treated with 0.75 $\mathrm{mM} \mathrm{H}_{2} \mathrm{O}_{2}$ for 0 (control cells), 6, 12 or $24 \mathrm{~h}$. Western blotting of nuclear extracts was used to determine Par- 4 protein levels. Par- 4 expression was normalized according to levels of the control nuclear protein histone H1. b Primary proximal tubular epithelial cells and HK-2 cells were treated with $0.75 \mathrm{mM} \mathrm{H}_{2} \mathrm{O}_{2}$ in the

effectively blocked the upregulated expression of phosphorylated Akt induced by transfection with Par-4-specific siRNA (fig. 4b).

Collectively, these results demonstrate that the PI3K/ Akt signaling pathway is a key mediator of the anti-apoptotic effects of Par-4-specific siRNA transfection of renal proximal tubular cells exposed to oxidative stress.

\section{Par-4 Silencing Reduces the Downregulated}

Expression of VEGF Induced by Oxidative Stress

Previous studies had demonstrated that exogenous VEGF promoted the survival of renal tubular epithelial cells and that activation of PI3K/Akt could increase VEGF transcription [27, 30, 31]. Thus, we determined whether VEGF was involved in Par-4 modulation of pri-

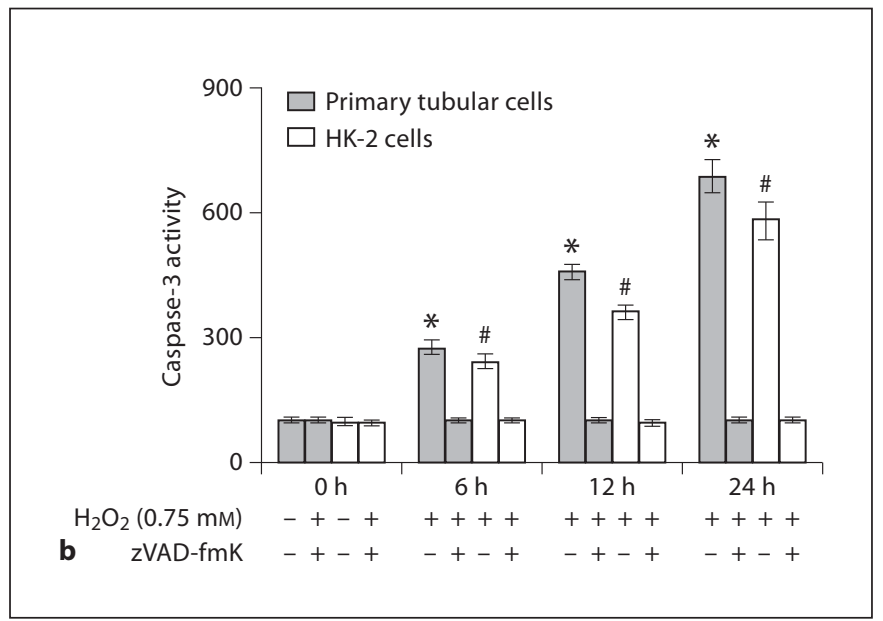

presence or absence of the caspase inhibitor zVAD-fmk $(50 \mu \mathrm{M})$ for 0 (control cells), 6, 12 or $24 \mathrm{~h}$. Cells were lysed and the caspase-3 activity of cytosolic extracts measured using the substrate DEVD-AFC. Caspase-3 activity levels were expressed relative to control cells. Results shown are representative of three independent experiments. Data are expressed as the mean \pm SD. ${ }^{*} \mathrm{p}<$ 0.05 compared to control primary tubular cells. ${ }^{\#} \mathrm{p}<0.05$ compared to control HK-2 cells. mary renal proximal tubule cell apoptosis. Control primary renal proximal tubular cells and HK-2 cells expressed and secreted VEGF protein (fig. 5). Treatment with $\mathrm{H}_{2} \mathrm{O}_{2}$ for $24 \mathrm{~h}$ reduced secretion and expression of VEGF protein by both primary renal proximal tubular cells and HK-2 cells (fig. 5). Transfection with Par-4-specific siRNA resulted in significant inhibition of the $\mathrm{H}_{2} \mathrm{O}_{2}$ induced VEGF downregulation (fig. 5) with VEGF expression being comparable to control conditions. Furthermore, treatment of Par-4 siRNA-treated cells with the PI3K/Akt inhibitor LY294002 resulted in reduced VEGF expression compared to control Par-4 siRNAtreated cells. These data indicate that the effect of Par-4 silencing upon VEGF expression was at least partially dependent upon the PI3K/Akt signaling pathway (fig. 5). 


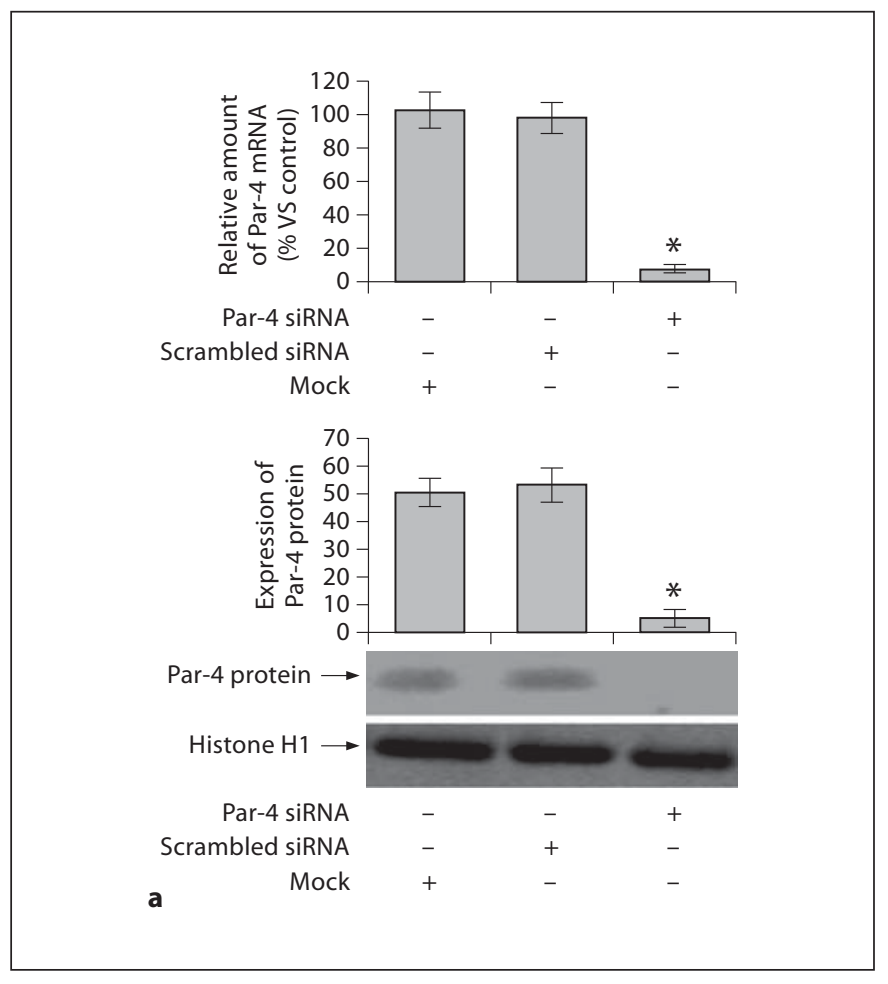

Fig. 3. Silencing of Par-4 gene expression significantly reduces Par-4 protein expression and protects human proximal tubular epithelial cells from $\mathrm{H}_{2} \mathrm{O}_{2}$-induced apoptosis. a Primary proximal tubular epithelial cells were transfected with either Par-4-specific siRNA, control scrambled siRNA or no siRNA (mock transfection). Par-4-specific siRNA significantly reduced Par-4 mRNA expression levels (assessed by real-time quantitative PCR analysis) and Par-4 protein levels (assessed by Western blots of whole cell extracts). ${ }^{*} \mathrm{p}<0.05$ compared to control and mock-transfected

\section{Discussion}

Oxidative stress contributes to cell damage in a variety of kidney diseases. Renal ischemia/reperfusion injury is the most common cause of acute renal failure and is a major clinical problem with high morbidity and mortality. Renal ischemia/reperfusion injury produces abundant ROS that overwhelm the renal scavenging capacity resulting in ROS-mediated lipid peroxidation, DNA damage and protein dysfunction that lead to acute renal failure and acute tubular necrosis $[1-5,11,12]$. In this study, our results demonstrate that $\mathrm{H}_{2} \mathrm{O}_{2}$ induced apoptosis in human renal proximal tubular epithelial cells as shown by other investigators. For example, Iqbal et al. [32] showed that $\mathrm{H}_{2} \mathrm{O}_{2}$ could induce peroxidation of microsomal membrane lipids and DNA damage in human renal proximal tubular epithelial cells.

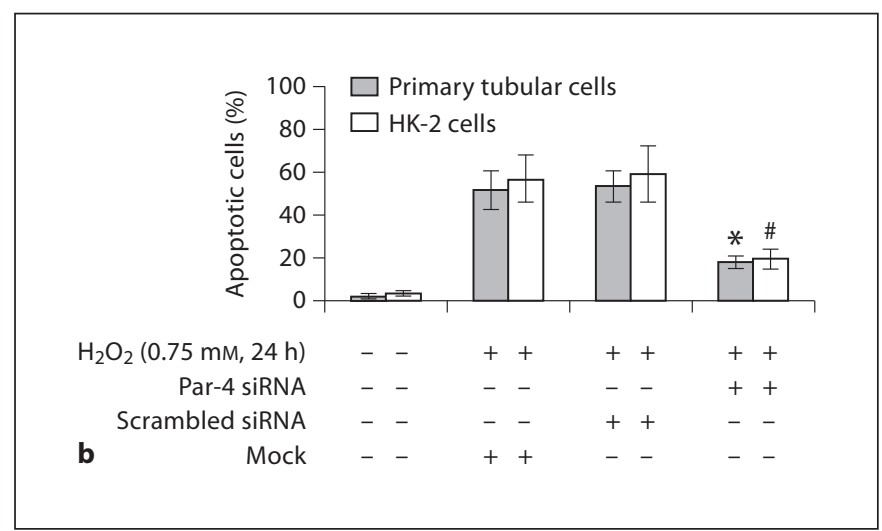

cells. b Following transfection with either Par-4-specific siRNA, control scrambled siRNA or no siRNA (mock transfection), proximal tubular epithelial cells and HK-2 cells were treated with 0.75 $\mathrm{mM} \mathrm{H}_{2} \mathrm{O}_{2}$ for $24 \mathrm{~h}$. Flow cytometric analysis was employed to assess apoptosis. ${ }^{*} \mathrm{p}<0.05$ compared to control and mock-transfected primary tubular cells. ${ }^{\#} \mathrm{p}<0.05$ compared to control and mock-transfected HK-2 cells. Results shown are representative of three independent experiments.

Although the pro-apoptotic protein Par-4 was initially identified as the product of a gene upregulated in prostate tumor cells undergoing apoptosis, there is growing evidence that Par-4 also regulates apoptosis in various cell lines [13-17]. We demonstrated that $\mathrm{H}_{2} \mathrm{O}_{2}$ induced a time-dependent increase of Par-4 expression in renal proximal tubular cells compared with control cells. Suppression of Par-4 expression using specific siRNA transfection greatly attenuated the level of apoptosis of renal proximal tubule cells exposed to $\mathrm{H}_{2} \mathrm{O}_{2}$ thereby implying that Par-4 was involved in oxidant injury of renal tubular epithelial cells. In view of previous work demonstrating that Par-4 expression enhanced activation of caspase family members in other cell lines [17], we evaluated caspase- 3 activity and found that $\mathrm{H}_{2} \mathrm{O}_{2}$ significantly enhanced activation of caspase-3 in renal proximal tubular cells. These results indicate that Par- 4 may play a critical 


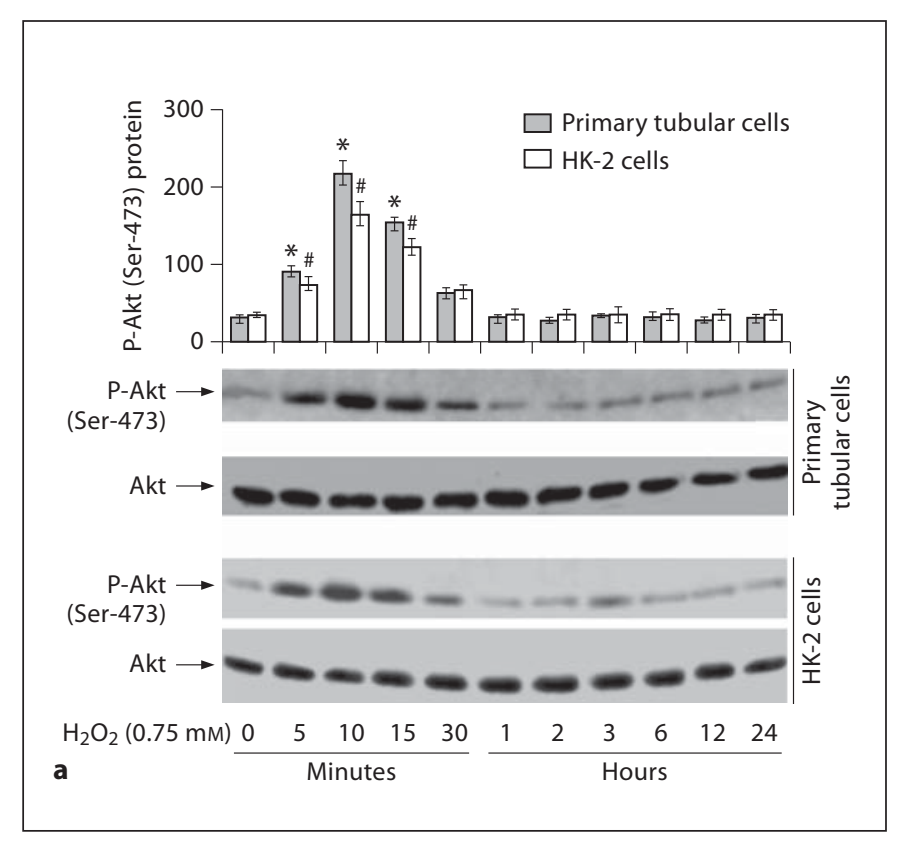

Fig. 4. Par-4 silencing increases phosphorylation of Akt in human proximal tubular epithelial cells treated with $\mathrm{H}_{2} \mathrm{O}_{2}$. a Primary proximal tubular epithelial cells and $\mathrm{HK}-2$ cells were treated with $0.75 \mathrm{mM} \mathrm{H}_{2} \mathrm{O}_{2}$ for the indicated times and lysates analyzed by Western blotting for phosphorylated Akt (Ser-473). ${ }^{*} \mathrm{p}<0.05$ compared to untreated control primary tubular cells $(0 \mathrm{~min}$ time point). ${ }^{\#} \mathrm{p}<0.05$ compared to untreated control HK-2 cells ( 0 min time point). b Following transfection with Par-4-specific siRNA, proximal tubular epithelial cells and HK-2 cells were treated with

role in the $\mathrm{H}_{2} \mathrm{O}_{2}$-induced apoptosis of human renal proximal tubular epithelial cells.

Although oxidative stress influences multiple antiand pro-apoptotic signaling pathways, we focused on the Akt pathway in the light of previous reports that Par-4 deficiency activates the Akt pathway in vivo and in several cellular systems $[18,33,34]$. In our study, Akt existed predominantly in an inactivated non-phosphorylated form in control renal proximal tubule cells, but was transiently activated and phosphorylated under conditions of oxidative stress. Western blot analysis showed that $\mathrm{H}_{2} \mathrm{O}_{2}$ treatment increased Akt phosphorylation (Ser-473) that peaked at $10 \mathrm{~min}$ and subsequently declined to basal levels within $3 \mathrm{~h}$. The decline of phosphorylated Akt might contribute to the molecular mechanisms responsible for $\mathrm{H}_{2} \mathrm{O}_{2}$-induced apoptosis in renal proximal tubular

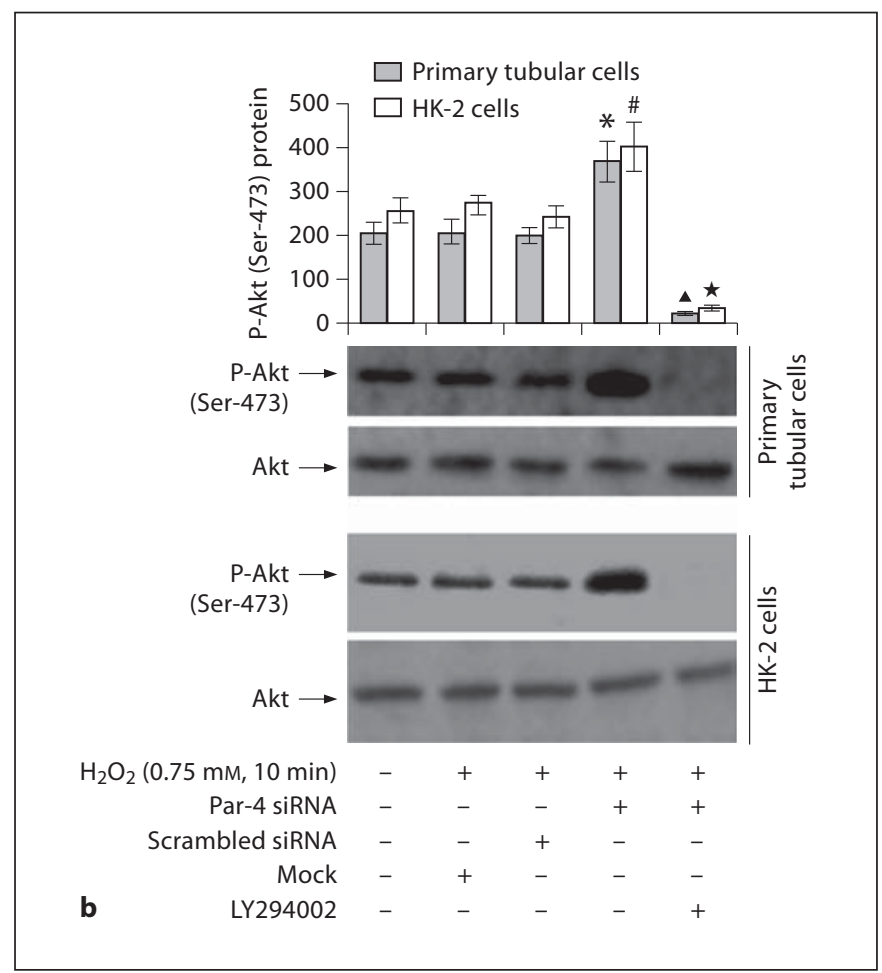

the PI3K inhibitor LY294002 $(20 \mu \mathrm{M})$ or medium alone for $1 \mathrm{~h}$. Cells were then exposed to $0.75 \mathrm{mM} \mathrm{H}_{2} \mathrm{O}_{2}$ for $10 \mathrm{~min}$ and Akt phosphorylation (Ser-473) detected by Western blotting. ${ }^{*} \mathrm{p}<$ 0.05 compared to non-transfected primary tubular epithelial cells not treated with $\mathrm{H}_{2} \mathrm{O}_{2}$ (first bar at left). ${ }^{\#} \mathrm{p}<0.05$ compared to non-transfected $\mathrm{HK}-2$ cells not treated with $\mathrm{H}_{2} \mathrm{O}_{2}$ (second bar at left). $\Delta \mathrm{p}<0.05$ compared to primary tubular cells transfected with Par- 4 siRNA and treated with $\mathrm{H}_{2} \mathrm{O}_{2} .{ }^{\star} \mathrm{p}<0.05$ compared to HK-2 cells transfected with Par- 4 siRNA and treated with $\mathrm{H}_{2} \mathrm{O}_{2}$.

epithelial cells. Furthermore, our results showed that silencing of Par-4 increased Akt phosphorylation in renal proximal tubular cells treated with $\mathrm{H}_{2} \mathrm{O}_{2}$. This effect was inhibited by the PI3K inhibitor LY294002, thereby suggesting that the PI3K/Akt signaling pathway was a key mediator of the anti-apoptotic effects of Par-4-specific siRNA treatment on renal proximal tubular epithelial cells exposed to oxidative stress.

The Par-4 protein can interact with $\mathrm{PKC} \zeta$ via the leucine zipper domain in the $\mathrm{COOH}$-terminal region and it has been reported that the Par- $4 / \mathrm{PKC} \zeta$ cassette is an important regulator of Akt activation. This effect most likely secondary to the ability of PKC $\zeta$ to directly phosphorylate Ser-124 of Akt with a subsequent impact on the phosphorylation of residue Ser- 473 that is critical for regulating Akt activity and function [35]. 


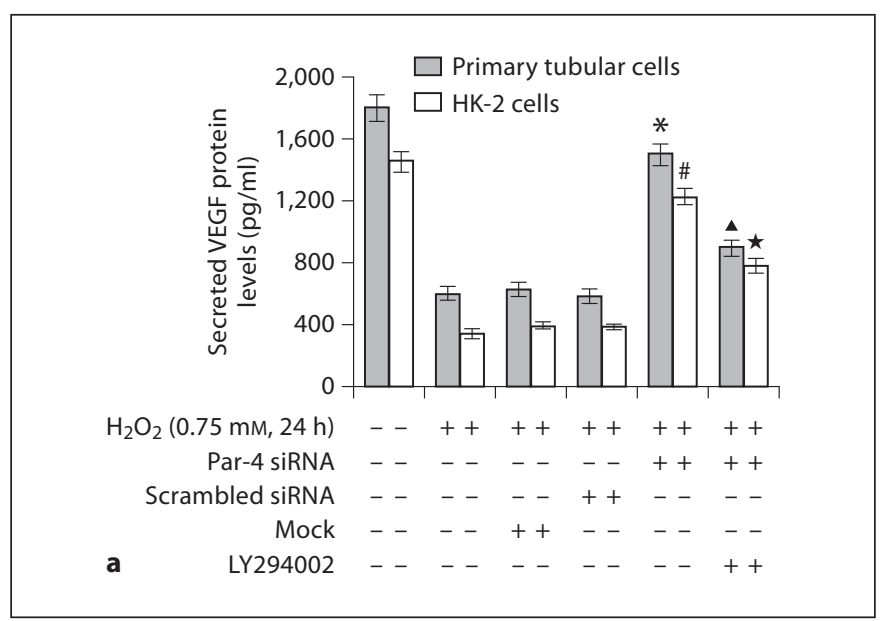

Fig. 5. Par-4 silencing ameliorates the downregulation of VEGF expression induced by $\mathrm{H}_{2} \mathrm{O}_{2}$. Following transfection with Par-4specific siRNA, primary human proximal tubular epithelial cells and HK-2 cells were treated with the PI3K inhibitor LY294002 (20 $\mu \mathrm{M})$ or medium alone for $1 \mathrm{~h}$. Cells were then exposed to $0.75 \mathrm{mM}$ $\mathrm{H}_{2} \mathrm{O}_{2}$ for $24 \mathrm{~h}$. a Levels of secreted VEGF in the culture supernatant were determined using ELISA kits. b Cytosolic levels of VEGF protein were detected by Western blotting with tubulin

In the present study, our results demonstrate that Par4-specific siRNA transfection significantly ameliorated the downregulation of VEGF protein expression induced by $\mathrm{H}_{2} \mathrm{O}_{2}$ treatment of renal proximal tubule cells. Moreover, PI3K/Akt inhibitor LY294002 effectively reduced VEGF expression, indicating the regulatory effects of Par-4 suppression on VEGF expression was partially PI3K/Akt signaling pathway. Consistently, previous studies had demonstrated that VEGF promoted survival of renal epithelial cells and activation of PI3K/Akt could increase VEGF transcription [27, 30, 31].

In conclusion, our results suggested that Par- 4 gene silencing protected renal proximal tubule cells from oxidative stress-induced apoptosis. The anti-apoptotic effect of Par-4 suppression is partially dependent on PI3K/Akt signal transduction, which ameliorated oxidative stressdownregulated expression of VEGF. Our findings may be useful to clarify the molecular mechanisms responsible for oxidative stress associated kidney disease, which benefits the therapy as well.
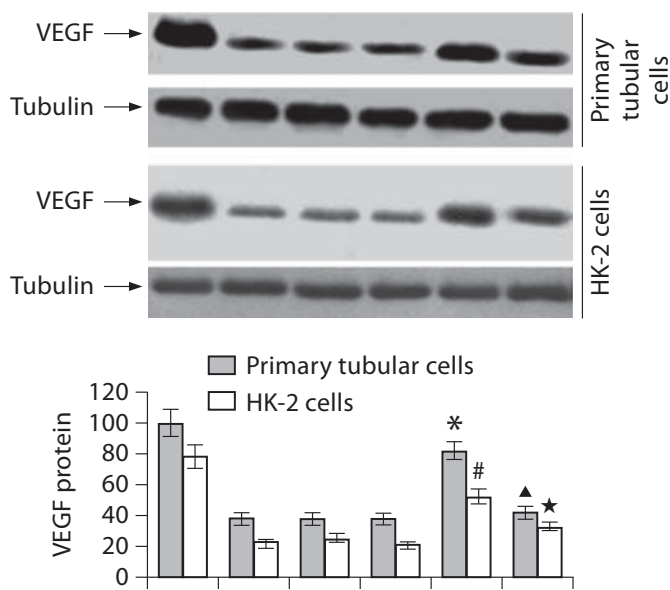

$\mathrm{H}_{2} \mathrm{O}_{2}(0.75 \mathrm{~mm}, 24 \mathrm{~h})-{ }_{-}+++++++++$

Par-4 SiRNA - - $--c_{-}++++$

Scrambled siRNA $\quad-\quad-\quad-c_{-}+\ldots$

Mock - - - + + - - - -

b $\quad \operatorname{LY} 294002 \ldots \ldots \ldots+\ldots+\ldots$

used as loading control. ${ }^{*} \mathrm{p}<0.05$ compared to control and mocktransfected primary tubular cells. ${ }^{\#} \mathrm{p}<0.05$ compared to control and mock-transfected HK-2 cells. ${ }^{\boldsymbol{\Delta}} \mathrm{p}<0.05$ compared to primary tubular cells transfected with Par-4-specific siRNA. ${ }^{\star} \mathrm{p}<$ 0.05 compared to HK-2 cells transfected with Par-4-specific siRNA. Results shown are representative of three independent experiments.

\section{Acknowledgments}

This work was supported by the Natural Science Foundation of Jiangsu Province of China (BK2007244), the National Natural Science Foundation of China (30872804), the Medical Academic Key Talent Program of Jiangsu Province in China (RC2007050), the Medical Grant of Scientific and Technological Development from the Health Department of Jiangsu Province in China (No. H200901), and the China Postdoctoral Science Foundation (20070411062).

References

Cachofeiro V, Goicochea M, de Vinuesa SG, Oubiña P, Lahera V, Luño J: Oxidative stress and inflammation, a link between chronic kidney disease and cardiovascular disease. Kidney Int Suppl 2008;111:S4-S9.

$\checkmark 2$ Cowley AW: Renal medullary oxidative stress, pressure natriuresis, and hypertension. Hypertension 2008;52:777-786.

- $3 \mathrm{Ha} \mathrm{H}$, Hwang IA, Park JH, Lee HB: Role of reactive oxygen species in the pathogenesis of diabetic nephropathy. Diabetes Res Clin Pract 2008;82(suppl 1):S42-S45. 
-4 Andreoli SP, Mallett CP, McAteer JA, Kempson SA, Fineberg N: Epidermal growth factor accelerates recovery of LLC-PK1 cells following oxidant injury. In Vitro Cell Dev Biol Anim 1998;34:824-830.

-5 Peraza MA, Cromey DW, Carolus B, Carter DE, Gandolfi AJ: Morphological and functional alterations in human proximal tubular cell line induced by low level inorganic arsenic: evidence for targeting of mitochondria and initiated apoptosis. J Appl Toxicol 2006:26:356-367.

-6 Filiopoulos V, Hadjiyannakos D, Takouli L, Metaxaki P, Sideris V, Vlassopoulos D: Inflammation and oxidative stress in end-stage renal disease patients treated with hemodialysis or peritoneal dialysis. Int J Artif Organs 2009;32:872-882.

-7 Ember A, Clark JS, Varjas T, Kiss I, Ember I, Baliga R, Arany I: The plant-derived natural compound Flavin 7 attenuates oxidative stress in cultured renal proximal tubule cells. In Vivo 2009;23:975-978.

8 Yun Y, Duan WG, Chen P, Wu HX, Shen ZQ, Qian ZY, Wang DH: Ischemic postconditioning modified renal oxidative stress and lipid peroxidation caused by ischemic reperfusion injury in rats. Transplant Proc 2009; 41:3597-3602.

-9 Pérez-Rojas JM, Cruz C, García-López P, Sánchez-González DJ, Martínez-Martínez CM, Ceballos G, Espinosa M, MeléndezZajgla J, Pedraza-Chaverri J: Renoprotection by $\alpha$-mangostin is related to the attenuation in renal oxidative/nitrosative stress induced by cisplatin nephrotoxicity. Free Radic Res 2009;43:1122-1132.

10 Devalaraja-Narashimha K, Singaravelu K, Padanilam BJ: Poly (ADP-ribose) polymerase-mediated cell injury in acute renal failure. Pharmacol Res 2005;52:44-59.

11 Versteilen AM, Di Maggio F, Leemreis JR, Groeneveld AB, Musters RJ, Sipkema P: Molecular mechanisms of acute renal failure following ischemia/reperfusion. Int J Artif Organs 2004;27:1019-1029.

12 Padanilam BJ: Cell death induced by acute renal injury: a perspective on the contributions of apoptosis and necrosis. Am J Physiol Renal Physiol 2003;284:F608-F627.

13 Gurumurthy S, Rangnekar VM: Par-4 inducible apoptosis in prostate cancer cells. J Cell Biochem 2004;91:504-512.

- 14 Fleischer A, Ghadiri A, Dessauge F, Duhamel M, Rebollo MP, Alvarez-Franco F, Rebollo A: Modulating apoptosis as a target for effective therapy. Mol Immunol 2006;43: 1065-1079.
15 Ranganathan P, Rangnekar VM: Regulation of cancer cell survival by Par-4. Ann NY Acad Sci 2005; 1059:76-85.

16 Culmsee C, Landshamer S: Molecular insights into mechanisms of the cell death program: role in the progression of neurodegenerative disorders. Curr Alzheimer Res 2006; 3:269-283.

17 Lu C, Chen JQ, Zhou GP, Wu SH, Guan YF, Yuan CS: Multimolecular complex of Par-4 and E2F1 binding to Smac promoter contributes to glutamate-induced apoptosis in human bone mesenchymal stem cells. Nucleic Acids Res 2008;36:5021-5032.

18 Lee TJ, Lee JT, Kim SH, Choi YH, Song KS, Park JW, Kwon TK: Overexpression of Par-4 enhances thapsigargin-induced apoptosis via down-regulation of XIAP and inactivation of Akt in human renal cancer cells. J Cell Biochem 2008;103:358-368.

19 Sheng S, Qiao M, Pardee AB: Metastasis and AKT activation. I Cell Physiol 2009;218:451454.

20 Weichhart T, Säemann MD: The PI3K/Akt/ mTOR pathway in innate immune cells: emerging therapeutic applications. Ann Rheum Dis 2008;67(suppl 3):iii70-74.

21 Pitt SC, Chen H: The phosphatidylinositol 3-kinase/Akt signaling pathway in medullary thyroid cancer. Surgery $2008 ; 144: 721-$ 724.

22 Assinder SJ, Dong Q, Kovacevic Z, Richardson DR: The TGF- $\beta$, PI3K/Akt and PTEN pathways: established and proposed biochemical integration in prostate cancer. Biochem J 2009;417:411-421.

$\checkmark 23$ De Vriese AS, Tilton RG, Elger M, Stephan CC, Kriz W, Lameire NH: Antibodies against vascular endothelial growth factor improve early renal dysfunction in experimental diabetes. J Am Soc Nephrol 2001;12:993-1000.

24 Flyvbjerg A, Dagnaes-Hansen F, De Vriese AS, Schrijvers BF, Tilton RG, Rasch R: Amelioration of long-term renal changes in obese type 2 diabetic mice by a neutralizing vascular endothelial growth factor antibody. Diabetes 2002;51:3090-3094

25 Cooper ME, Vranes D, Youssef S, Stacker SA, Cox AJ, Rizkalla B, Casley DJ, Bach LA, Kelly DJ, Gilbert RE: Increased renal expression of vascular endothelial growth factor (VEGF) and its receptor VEGFR-2 in experimental diabetes. Diabetes 1999;48:22292239.
26 Tsuchida K, Makita Z, Yamagishi S, Atsumi T, Miyoshi H, Obara S, Ishida M, Ishikawa S, Yasumura K, Koike T: Suppression of transforming growth factor $\beta$ and vascular endothelial growth factor in diabetic nephropathy in rats by a novel advanced glycation end product inhibitor, OPB-9195. Diabetologia 1999;42:579-588.

27 Pore N, Liu S, Shu HK, Li B, Haas-Kogan D, Stokoe D, Milanini-Mongiat J, Pages G, O'Rourke DM, Bernhard E, Maity A: Sp1 is involved in Akt-mediated induction of VEGF expression through an HIF-1-independent mechanism. Mol Biol Cell 2004;15: 4841-4853.

28 Cui XL, Ding Y, Alexander LD, Bao C, AlKhalili OK, Simonson M, Eaton DC, Douglas JG: Oxidative signaling in renal epithelium: critical role of cytosolic phospholipase $\mathrm{A}_{2}$ and p38(SAPK). Free Radic Biol Med 2006;41:213-221.

29 Porter AG, Jänicke RU: Emerging roles of caspase-3 in apoptosis. Cell Death Differ 1999;6:99-104.

30 Villegas G, Lange-Sperandio B, Tufro A: Autocrine and paracrine functions of vascular endothelial growth factor (VEGF) in renal tubular epithelial cells. Kidney Int 2005;67: 449-457.

-31 Liang Z, Brooks J, Willard M, Liang K, Yoon Y, Kang S, Shim H: CXCR4/CXCL12 axis promotes VEGF-mediated tumor angiogenesis through Akt signaling pathway. Biochem Biophys Res Commun 2007;359:716722 .

32 Iqbal M, Okazaki Y, Okada S: In vitro curcumin modulates ferric nitrilotriacetate (Fe-NTA) and hydrogen peroxide $\left(\mathrm{H}_{2} \mathrm{O}_{2}\right)$ induced peroxidation of microsomal membrane lipids and DNA damage. Teratog Carcinog Mutagen 2003;suppl 1:151-160.

33 Diaz-Meco MT, Moscat J: Akt regulation and lung cancer: a novel role and mechanism of action for the tumor suppressor Par-4. Cell Cycle 2008;7:2817-2820.

- 34 Joshi J, Fernandez-Marcos PJ, Galvez A, Amanchy R, Linares JF, Duran A, Pathrose $\mathrm{P}$, Leitges M, Cañamero M, Collado M, Salas C, Serrano M, Moscat J, Diaz-Meco MT: Par4 inhibits Akt and suppresses Ras-induced lung tumorigenesis. EMBO J 2008;27:21812193.

35 Joshi J, Fernandez-Marcos PJ, Galvez A, Amanchy R, Linares JF, Duran A, Pathrose P, Leitges M, Cañamero M, Collado M, Salas C, Serrano M, Moscat J, Diaz-Meco MT: Par4 inhibits Akt and suppresses Ras-induced lung tumorigenesis. EMBO J 2008;27:21812193. 